
\section{$E_{\text {chiture }}$}

${ }^{1}$ Department of Respiratory Medicine, Galway University Hospital, Newcastle Road, Galway, Ireland

${ }^{2}$ Department of Radiology, Galway University Hospital, Galway, Ireland

${ }^{3}$ Department of Cardiothoracic Surgery, Mater Miscorderae University Hospital, Eccles Street, Dublin 7, Ireland ${ }^{4}$ Department of Imaging, Imperial College Healthcare NHS Trust, Hammersmith Hospital, London, UK

\section{Correspondence to} Dr Robert M Rutherford, Department of Respiratory Medicine, Galway University Hospitals, Newcastle Road, Galway, Ireland: Robert.rutherford@hse.ie

Received 6 March 2013 Revised 22 April 2013 Accepted 2 May 2013 Published Online First 24 May 2013

\title{
An unusual cause of haemoptysis in a smoker
}

\author{
M J McDonnell, ${ }^{1}$ J Garvey, D G Lohan, ${ }^{1,2} \mathrm{G}$ J O'Sullivan, ${ }^{2} \mathrm{~K}$ Redmond, ${ }^{3}$ \\ J E Jackson, ${ }^{4}$ R M Rutherford ${ }^{1}$
}

\section{CASE DESCRIPTION}

A 33-year-old Caucasian male smoker presented to our rapid access lung cancer clinic with a single episode of moderate haemoptysis and no other respiratory or systemic symptoms. There was no relevant past medical history. As an adopted child he was unaware of any significant family history. The only finding on clinical examination was decreased air entry on the right side. Laboratory tests were all normal. Chest $\mathrm{x}$-ray demonstrated a small right hemithorax with marked mediastinal displacement to the right, increased soft tissue opacity adjacent to the right side of the mediastinum causing widening of the right paratracheal stripe and loss of silhouette of the right heart border, and increased interstitial opacity throughout the right lung (figure 1A). A CT scan of the thorax confirmed the presence of a large amount of abnormal low attenuation soft tissue around the right side of the mediastinum, which also involved the azygo-oesophageal space causing considerable thickening of the oesophageal wall (figure 1B), a small right hemithorax, bronchial and non-bronchial systemic artery hypertrophy and widespread interlobular septal thickening (figure $1 \mathrm{C}$ ). No endobronchial lesion was noted on bronchoscopy but multiple superficial vessels were present in the trachea and entrance to the right main bronchus (figure 1D). Bronchoalveolar lavage microbiology and cytology were negative. Spirometry was within the normal range. Ultrasound of the abnormal mediastinal soft tissue suggested the presence of numerous blood vessels within which slow flow could be demonstrated on Doppler. Attempted pneumonectomy was abandoned due to severe blood loss. Future embolisation is planned to reduce the bleeding risk.

\section{ANSWER See page 99}

Contributors All authors have made substantial contributions to the conception and design of the study or acquisition and interpretation of imaging data; drafting the article or revising it critically for important intellectual content; and final approval of the version to be submitted. RMR is responsible for the overall content as guarantor.

Competing interests None.

Patient consent Obtained.

Provenance and peer review Not commissioned; externally peer reviewed.

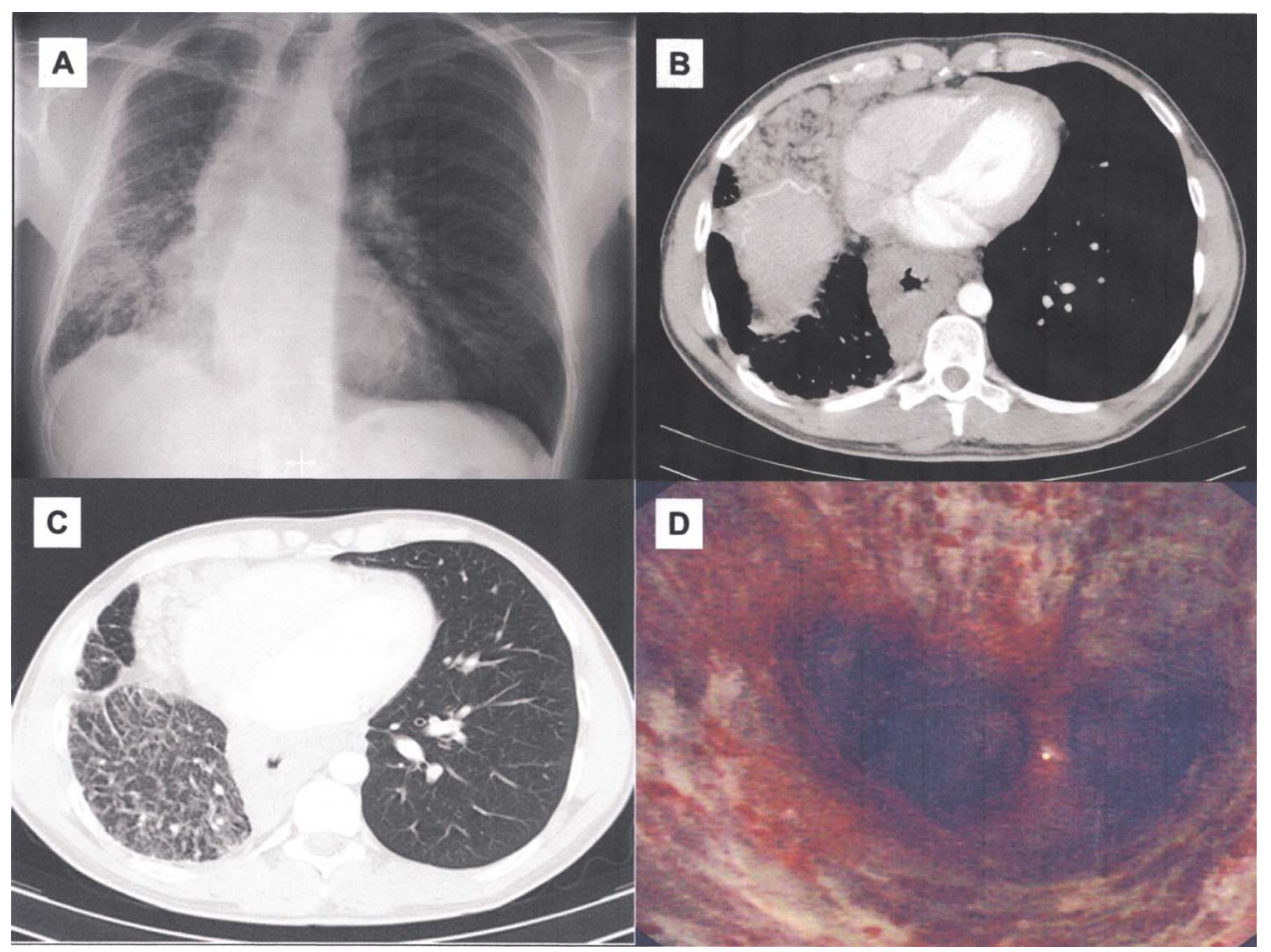

Figure 1 (A) Chest $x$-ray showing a small right hemithorax with right paramediastinal soft tissue and interstitial shadowing in the right lung. (B) Axial CT image at the level of the right hemidiaphragm showing abnormal right paracardiac and paraoesophageal soft tissue. Note also the enlarged right inferior phrenic artery coursing over the top of the liver. (C) Axial CT image through the lung bases showing widespread right-sided interlobular septal thickening which was present throughout the right lung. (D) Bronchoscopy shows multiple superficial vessels in the trachea and origin of the right main bronchus. 


\section{An unusual cause of haemoptysis in a smoker}

\section{ANSWER}

From the question on page 93.

\section{DISCUSSION}

The combination of a small right hemithorax, abnormal right paramediastinal soft tissue, bronchial and non-bronchial systemic artery hypertrophy and interlobular septal thickening is consistent with a diagnosis of isolated congenital unilateral pulmonary vein atresia.

This condition, without associated cardiac malformation, is very rare with fewer than 50 reported cases worldwide. ${ }^{1-5}$ Diagnosis is usually made in infancy. To our knowledge, only five adult cases have been described (table 1). ${ }^{1-4}$ Recurrent pulmonary infections (affected side), exertional dyspnoea and haemoptysis are the predominant presenting complaints. ${ }^{2} 3$

Imaging features include:

- Bronchial and non-bronchial systemic artery hypertrophy which, through normal systemic artery to pulmonary artery (PA) anastomoses, causes reversal of blood flow within the ipsilateral PA. Figure 2A shows a hypertrophied right bronchial artery (arrowhead) and increased enhancement of the right PA (arrow) compared with the left. The reversal of flow is further confirmed by the complete absence of activity in the right lung on a technetium-99 m macroaggregate albumin perfusion lung scan (figure 2B).

- Complete absence of ipsilateral central pulmonary veins with a smooth contour to the right side of the left atrium (figure 3).

- Ipsilateral interlobular septal thickening due to severe pulmonary venous outflow obstruction (figure 1C).

- Abnormal paramediastinal soft tissue which is largely made up of venous collaterals. ${ }^{2}$

Pulmonary vein atresia is caused by late failure of incorporation of the common pulmonary vein into the left atrium. ${ }^{4}$ Mortality approaches $50 \%$ if untreated. ${ }^{1}{ }^{3}$ Management may be conservative. Outcome data from attempted restorative surgery are poor. ${ }^{3}{ }^{4}$ Pneumonectomy, if possible, is the preferred treatment choice to avoid life-threatening haemoptysis. ${ }^{1-3}$

Table 1 Reported cases of isolated unilateral pulmonary vein atresia in adults

\begin{tabular}{|c|c|c|c|c|c|}
\hline Reference & Symptoms & $\begin{array}{l}\text { Age at } \\
\text { diagnosis }\end{array}$ & Gender & $\begin{array}{l}\text { Side } \\
\text { affected }\end{array}$ & Surgery \\
\hline Harrison et al ${ }^{1}$ & Haemoptysis, haematemesis & 27 & $\mathrm{~F}$ & $\mathrm{~L}$ & Pneumonectomy \\
\hline Heyneman et $a l^{2}$ & Dyspnoea, pulmonary artery hypertension & 25 & $\mathrm{~F}$ & $\mathrm{R}$ & Pneumonectomy \\
\hline Heyneman et $a l^{2}$ & Dyspnoea, haemoptysis & 43 & $\mathrm{~F}$ & $\mathrm{R}$ & Pneumonectomy \\
\hline Zhang et $a l^{3}$ & Haemoptysis & 22 & $\mathrm{~F}$ & $\mathrm{R}$ & Pneumonectomy \\
\hline SavasBosbas et al ${ }^{4}$ & Dyspnoea & 20 & $\mathrm{~F}$ & $\mathrm{R}$ & Conservative \\
\hline Current patient & Haemoptysis & 33 & M & $\mathrm{R}$ & Attempted pneumonectomy \\
\hline
\end{tabular}

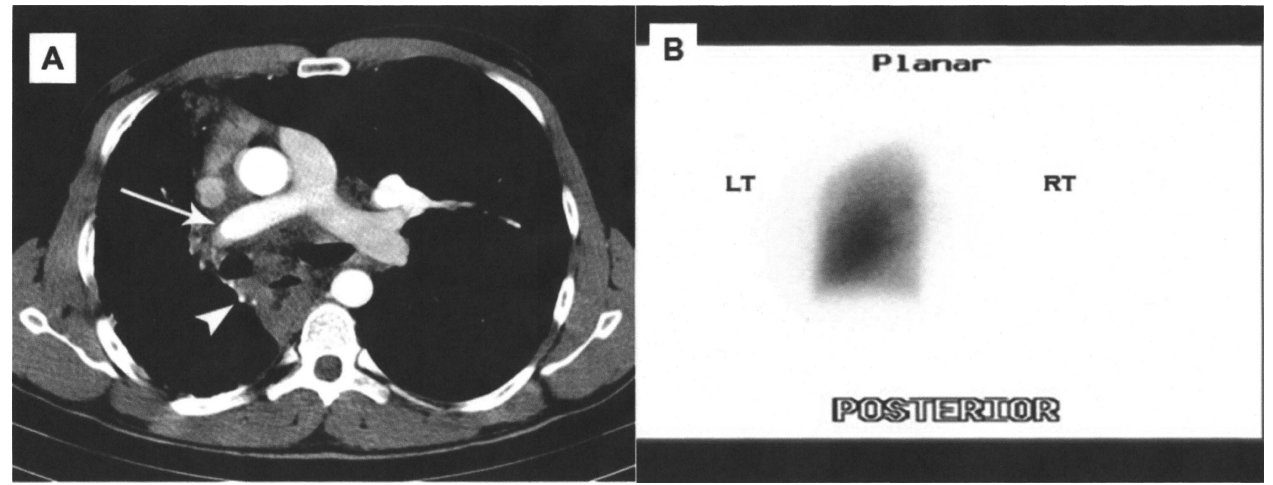

Figure 2 (A) Axial contrast-enhanced CT image at the level of the pulmonary artery bifurcation showing increased enhancement of the right pulmonary artery (arrow) compared with the left side and a hypertrophied bronchial artery (arrowhead). (B) Posterior lung perfusion scan (performed to confirm absence of antegrade flow in the right pulmonary artery) demonstrating absence of perfusion to the right lung. Ventilation to the right lung was normal (not shown). 


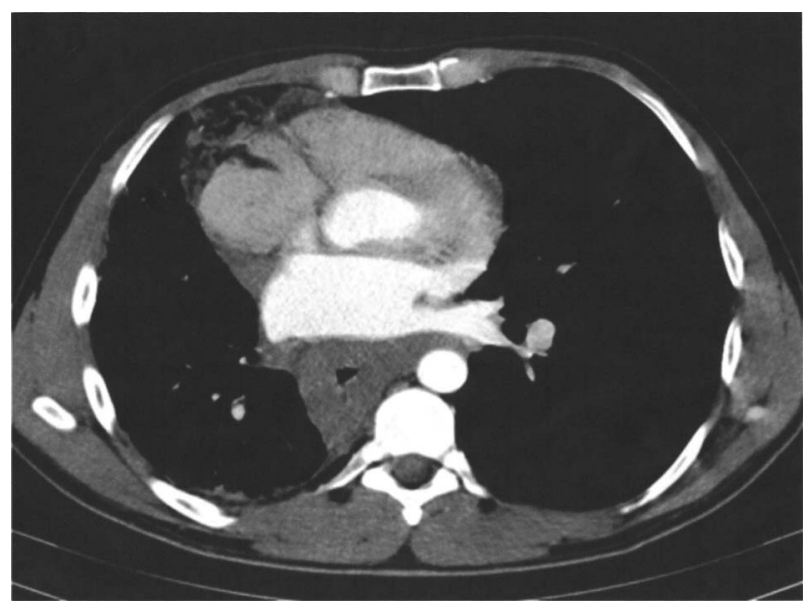

\section{REFERENCES}

1 Harrison JK, Hearne SE, Baker WA, et al. Oesophageal varices in association with unilateral pulmonary vein atresia. Cathet Cardiovasc Diagn 1996;38: 387-92.

2 Heyneman L, Nolan RL, Harrison JK. Congenital unilateral pulmonary vein atresia: radiologic findings in three adult patients. AJR Am J Roentgenol 2001;177: 681-5.

3 Zhang $\mathrm{M}, \mathrm{Wu} \mathrm{QC}$, Zhang $\mathrm{C}$, et al. Isolated unilateral pulmonary vein atresia in adult patients: a case report and literature review. Heart Surg Forum 2010;13:370-2.

4 SavasBosbas S, Varan B, Ackay S. Right pulmonary venous atresia: a case report and review of literature. Tuberk Toraks 2012;60:254-7.

5 Cabrera A, Vazquez C, Lekuona I. Isolated atresia of the left pulmonary veins. Int J Cardiol 1985;7:213-19.

Figure 3 CT image through the left atrium showing a smooth contour to the right side of this chamber due to complete absence of the right-sided pulmonary veins. 